\title{
BMJ Global Health The cost of illness for childhood clinical pneumonia and invasive pneumococcal disease in Nigeria
}

\author{
Aishatu Lawal Adamu (D) ,1,2,3 Boniface Karia, ${ }^{1}$ Musa M Bello, ${ }^{3,4}$ \\ Mahmoud G Jahun, ${ }^{5,6}$ Safiya Gambo, ${ }^{7}$ John Ojal, ${ }^{1,2}$ Anthony Scott, ${ }^{1,2}$ \\ Julie Jemutai, ${ }^{8}$ Ifedayo M Adetifa (1) ${ }^{1,2}$
}

To cite: Adamu AL, Karia B, Bello MM, et al. The cost of illness for childhood clinical pneumonia and invasive pneumococcal disease in Nigeria. BMJ Global Health 2022;7:e007080. doi:10.1136/ bmjgh-2021-007080

Handling editor Lei Si

- Additional supplemental material is published online only. To view, please visit the journal online (http://dx.doi.org/10. 1136/bmjgh-2021-007080)

JJ and IMA contributed equally.

Received 4 August 2021 Accepted 3 January 2022

Check for updates

(C) Author(s) (or their employer(s)) 2022. Re-use permitted under CC BY. Published by BMJ.

For numbered affiliations see end of article.

Correspondence to Dr Aishatu Lawal Adamu; ayshaad2@gmail.com

\section{ABSTRACT}

Background Pneumococcal disease contributes significantly to childhood morbidity and mortality and treatment is costly. Nigeria recently introduced the pneumococcal conjugate vaccine (PCV) to prevent pneumococcal disease. The aim of this study is to estimate health provider and household costs for the treatment of pneumococcal disease in children aged $<5$ years (U5s), and to assess the impact of these costs on household income.

Methods We recruited U5s with clinical pneumonia, pneumococcal meningitis or pneumococcal septicaemia from a tertiary level hospital and a secondary level hospital in Kano, Nigeria. We obtained resource utilisation data from medical records to estimate costs of treatment to provider, and household expenses and income loss data from caregiver interviews to estimate costs of treatment to households. We defined catastrophic health expenditure (CHE) as household costs exceeding $25 \%$ of monthly household income and estimated the proportion of households that experienced it. We compared CHE across tertiles of household income (from the poorest to least poor).

Results 0 480 participants recruited, $244 \mathrm{had}$ outpatient pneumonia, and 236 were hospitalised with pneumonia (117), septicaemia (66) and meningitis (53). Median (IQR) provider costs were US $\$ 17$ (US\$14-22) for outpatients and US\$272 (US\$271-360) for inpatients. Median household cost was US\$51 (US\$40-69). Overall, 33\% of households experienced CHE, while $53 \%$ and $4 \%$ of the poorest and least poor households, experienced CHE, respectively. The odds of CHE increased with admission at the secondary hospital, a diagnosis of meningitis or septicaemia, higher provider costs and caregiver having a nonsalaried job.

Conclusion Provider costs are substantial, and households incur treatment expenses that considerably impact on their income and this is particularly so for the poorest households. Sustaining the PCV programme and ensuring high and equitable coverage to lower disease burden will reduce the economic burden of pneumococcal disease to the healthcare provider and households.
Key questions

What is already known?

- Children $<5$ years have the highest incidence of pneumonia and invasive pneumococcal disease (IPD) and Nigeria bears the largest burden in sub-Saharan Africa.

- Pneumococcal conjugate vaccine (PCV) was introduced in Nigeria in 2016 to reduce the burden of pneumococcal disease.

- PCV is currently subsidised through Gavi (the Vaccine Alliance) financial support and Nigeria will transition to full self-financing in a few years.

- There is no contextual evidence in Nigeria on economic burden of IPD to the health system and society that can support longer term investments in PCV when Gavi co-financing terminates.

What are the new findings?

- Treatment of one hospitalised episode of pneumococcal disease cost on average, US $\$ 300$ to the provider, and US\$83 to the household with significant variation by clinical syndrome and level of care.

- Overall, one-third of the households encountered costs that were catastrophic (ie, $>25 \%$ of household income).

- Burden of catastrophic health expenditure varied by household income tertile ranging from $4 \%$ in the least poor households (highest income tertile) to $53 \%$ in the poorest households (lowest income tertile).

- Despite the short illness duration, pneumococcal disease syndromes result in huge economic costs to providers and households.

What do the new findings imply?

- Sustaining the PCV programme and achieving high PCV coverage has the potential of saving resources at both provider and household level.

- Households are at risk of further impoverishment from catastrophic expenses associated with treatment of pneumococcal disease.

- This risk can also be significantly reduced by PCV.

\section{INTRODUCTION}

Introduction of the pneumococcal conjugate vaccine $(\mathrm{PCV})$ has significantly reduced the 
global burden of pneumococcal disease. ${ }^{1}$ Despite availability of effective vaccination, pneumococcal disease syndromes remain as leading causes of preventable morbidity, mortality and economic burden, particularly among children aged $<5$ years (U5s) and in low-income and middle-income countries (LMICs). ${ }^{12}$ In 2015, there were still $\sim 9$ million cases of invasive pneumococcal disease (IPD) in U5 children resulting in over 300000 deaths despite this being a significant decline of $>60 \%$ from the prevaccination PCV era. ${ }^{13}$ Slow uptake and suboptimal coverage of PCV are partly responsible for a disproportionate pneumococcal disease burden in LMICs in the post-PCV era. ${ }^{1}$ Unsurprisingly, pneumococcal diseases are associated with substantial annual economic health system costs of about US $\$ 13.7$ billion and societal costs of US $\$ 14.3$ billion globally. ${ }^{4}$ Although associated with substantial vaccine and delivery costs, ranging between US $\$ 52$ in Africa to US $\$ 599$ in Europe per vaccinated child, the introduction of PCVs to infant immunisation programmes is expected to provide savings estimated as US $\$ 3.2$ billion from averted hospital visits and care, and an additional US $\$ 2.6$ billion from societal costs globally. ${ }^{4}$ Economic cost studies on pneumococcal diseases report substantial costs of treatment to healthcare provider, households and families, with significant out-of-pocket (OOP) payment for health particularly in LMICs. ${ }^{5-12}$ OOP payment for healthcare can result in catastrophic expenses capable of driving households further into poverty.

With $>1$ million pneumococcal disease cases resulting in nearly 50000 deaths among U5s in 2015, Nigeria has the highest burden of pneumococcal disease in subSaharan Africa (sSA). ${ }^{1}$ Approximately $40 \%$ of Nigeria's population live below the poverty line, and $15 \%$ of the population incur healthcare expenses from an illness episode that exceeds $10 \%$ of their household income annually. ${ }^{1314}$ In addition, $2.3 \%$ are pushed into poverty by these health expenses. ${ }^{14}$

Financing of healthcare in Nigeria is via multiple and largely uncoordinated channels. ${ }^{15}$ It has one of the lowest health insurance coverage in sSA because the National Health Insurance Scheme currently targets persons employed in the formal sector, which represent about $5 \%$ of the population. ${ }^{16} 17$ The huge informal sector largely finances healthcare through OOP payment that are over three-quarters of total expenditure on health. ${ }^{18}$ The consequences of the huge pneumococcal disease burden and limited financial protection, especially for the poor, extend beyond the clinical as households are at high risk of impoverishment. Additionally, to avoid such unexpected financial burden, households can delay or refrain from seeking healthcare and this ultimately results in greater costs and/or poorer outcomes. ${ }^{19}$ Existing mechanisms to provide financial protection to households range from subsidised services for vulnerable populations such as U5s and pregnant women, to the recent expansion of community-based health insurance (CBHI) to the informal sector. ${ }^{2021}$
Ahead of Nigeria completing the transition to full selffinancing of PCV in 2028, ${ }^{22}$ data on the economic burden of pneumococcal diseases will help inform the policy required to assure sustainability of the PCV programme. A current description of the costs of treating childhood pneumococcal diseases in Nigeria is lacking highlighting a significant data gap.

The objectives of this study are to: (1) to estimate the provider costs of outpatient and inpatient clinical pneumonia, and inpatient pneumococcal septicaemia and meningitis; (2) to estimate the household costs of hospitalised clinical pneumonia, and pneumococcal meningitis and bacteraemia; and (3) to assess the economic impact to households of hospitalisation with clinical pneumonia, and pneumococcal septicaemia and meningitis among U5s in Kano, northern Nigeria.

\section{METHODS \\ Study design and setting}

This was a cross-sectional study conducted at the two largest paediatrics units in Kano, Kano State in northern Nigeria-Aminu Kano Teaching Hospital (AKTH) and Murtala Muhammed Specialist Hospital (MMSH) which serve an overlapping catchment population. AKTH is a Federal Government Teaching Hospital and MMSH is a State Government Secondary Hospital. Kano is the capital city of Kano state and covers approximately 8 out of the 44 local government areas (LGAs) of the state. However, catchment population of both hospitals includes other LGAs outside the city and neighbouring states. The description of the hospitals is shown in table 1. Kano is the most densely populated state in the region with an estimated population of 12.2 million ( 1.3million U5s) occupying $20760 \mathrm{~km}^{2} .{ }^{23}{ }^{24}$ About $55 \%$ of the population in Kano state reside in households below the poverty line. ${ }^{13}$ The infant and U5 mortality per 1000 live births in Kano (National) were 112 (70) and 203 (120) in 2018. ${ }^{25}$

\section{Study population}

Children were recruited prospectively and were eligible if aged 1-59 months, presented to AKTH or MMSH and had at least one of three possible diagnoses of interest. These were (1) clinical pneumonia, (2) pneumococcal septicaemia and (3) pneumococcal meningitis. We excluded children that died during admission.

We used the formula below ${ }^{26}$ to estimate the minimum sample sizes for (1) outpatient clinical pneumonia; (2) inpatient pneumonia; and (3) septicaemia and meningitis:

$$
n=\frac{(\mathrm{Z} \sigma)^{2}}{e^{2}}
$$

Where: $\mathrm{n}=$ minimum sample size.

$\mathrm{Z}=$ the standard normal deviate for the desired confidence level (ie, $\mathrm{Z}=1.96$ for $95 \%$ confidence).

$\sigma=\mathrm{SD}$ deviation of respective mean costs reported from previous studies. ${ }^{89}$ 


\begin{tabular}{|c|c|c|c|c|c|c|}
\hline Hospital & Hospital type & $\begin{array}{l}\text { No of beds - } \\
\text { total/paediatric }\end{array}$ & $\begin{array}{l}\text { Paediatric } \\
\text { outpatient } \\
\text { clinic turnover } \\
\text { (weekly) }\end{array}$ & $\begin{array}{l}\text { User charging } \\
\text { policy }\end{array}$ & $\begin{array}{l}\text { Catchment } \\
\text { population }\end{array}$ & Source \\
\hline AKTH & $\begin{array}{l}\text { Tertiary-with } \\
\text { paediatric } \\
\text { outpatient clinic } \\
\text { offering primary } \\
\text { level care }\end{array}$ & $750 / 55$ & $\sim 1400$ & $\begin{array}{l}\text { User fees charged } \\
\text { at } 50 \% \text { of adult } \\
\text { rate }\end{array}$ & $\begin{array}{l}\text { Residents of Kano } \\
\text { and neighbouring } \\
\text { states }\end{array}$ & $\begin{array}{l}\text { AKTH paediatric } \\
\text { and hospital } \\
\text { record units }\end{array}$ \\
\hline MMSH & $\begin{array}{l}\text { Secondary- } \\
\text { with paediatric } \\
\text { outpatient clinic } \\
\text { offering primary } \\
\text { level care }\end{array}$ & $1000 / 56$ & $\sim 2100$ & $\begin{array}{l}\text { Consultation and } \\
\text { admission provided } \\
\text { free to children }<14 \\
\text { years. } \\
\text { Patients pay for } \\
\text { investigations and } \\
\text { buy drugs out- } \\
\text { of-pocket if not } \\
\text { available }\end{array}$ & $\begin{array}{l}\text { Residents of Kano } \\
\text { and neighbouring } \\
\text { states }\end{array}$ & $\begin{array}{l}\text { MMSH } \\
\text { paediatric and } \\
\text { hospital record } \\
\text { units }\end{array}$ \\
\hline
\end{tabular}

AKTH, Aminu Kano Teaching Hospital; MMSH, Murtala Muhammed Specialist Hospital.

$\mathrm{e}=$ precision or smallest desirable margin of error allowable for estimation of the respective costs.

Sample sizes of 100, 50 and 30 were expected to provide a cost estimate for outpatient clinical pneumonia, inpatient pneumonia and septicaemia and meningitis based on SD ( \pm precision) of US $\$ 5$ ( \pm US\$1), US\$21 ( \pm US $\$ 6$ ) and US\$33 ( \pm US\$12), respectively. ${ }^{8} 927$

\section{Data collection}

We recruited outpatient pneumonia cases and interviewed caregivers on the day of diagnosis. For inpatient pneumonia cases, eligible children admitted from 08:00 to 16:00 were recruited on the day of admission; those admitted from 16:00 to 08:00 the next morning were enrolled on the next day. For septicaemia and meningitis cases, participants were recruited when confirmatory laboratory results were available. We collected data between January and October 2020. For each hospital, we recruited a volunteer nurse not directly involved in clinical care to collect data. We used structured quantitative tools adapted from a similar study in The Gambia for data collection. ${ }^{9}$

We extracted resource use data such as length of hospital stay, type and quantity of medications and intravenous fluids used, laboratory investigations and other specialised services including blood transfusion and use of oxygen from patients' records, case folders, prescriptions and laboratory request forms. We obtained unit costs of hospital resources, for example, medication, fluids used from the respective hospitals (see online supplemental table S1).

Sociodemographic characteristics, OOP costs, nonmedical expenses, productivity time loss, household income and sources of finances used to pay the treatment costs were obtained through caregiver interviews. Additional data on household income and sources of finances used to pay the treatment costs were also collected.

\section{Cost components}

We collected provider costs, and direct and indirect household costs.

\section{Provider costs}

Provider costs included costs of direct healthcare services, that is, costs of medications, laboratory investigations, intravenous fluids, oxygen, blood transfusion and inpatient bed-day. We used full costs for drugs and only applied dose-specific costs if the drug was re-useable and the residuals amounted to another full dose. For instance, for a re-useable drug, if a unit dose was $1000 \mathrm{mg}$ and $500 \mathrm{mg}$ was administered, the cost per dose would be half of the unit cost. We obtained cost of oxygen from the nursing unit, and for blood transfusion, we used previously published costs. ${ }^{28}$

The inpatient bed-day is the daily stay cost or the 'hotel' component and comprises costs of food, personnel and utilities. We used the average 2020 admission charge for AKTH and assumed admission costs at MMSH to be $60 \%$ of AKTH since admission is 'free' to patients at MMSH. Studies have found up to $60 \%-70 \%$ differences in bedday costs between tertiary-level and secondary-level hospitals. $^{89}$

\section{Household costs}

We collected direct healthcare costs to households which are user fees related to consultations, investigations and medications incurred from date of admission to date of discharge. Non-healthcare costs were the costs of transportation, accommodation and feeding incurred during admission (from date of admission to date of discharge) by main and accompanying caregiver. The accompanying caregiver was defined as any household member that assisted the main caregiver with care of the patient during the admission. Preadmission costs data were collected either on the day of recruitment or 
on the earliest convenient day for the caregiver, while data on costs incurred over the course of admission were obtained at or close to discharge.

We collected data on caregiver's income and productivity time loss due to time away from their usual activities owing to illness.

\section{Data analysis}

Data were analysed using Stata V.15.1 (Stata Corp LP). All costs were converted to US\$ using average 2020 conversion rates 1 US $\$=360.5 \mathrm{NGN}$ (Central bank of Nigeria) $)^{29}$

We summed up the components of respective cost categories for provider costs and direct household costs. We estimated indirect costs using the human-capital approach (HCA) by estimating income lost by caregiver(s) due to absence from work per day spent caring for the child. Self-employed caregivers were asked to give an estimate of daily earnings while those on monthly salary were asked to state their monthly wage from which daily income was calculated. Indirect costs were then calculated as daily income multiplied by the number of days taken off from work.

We present costs from the health provider and household's perspectives along with their components separately as means with SD, and medians with IQR. We used Kruskal-Wallis test to assess differences in costs between disease categories and Wilcoxon rank-sum test to compare costs between the two hospitals.

We evaluated the impact of health expenditures on available household resources by assessing direct, indirect and total costs as respective proportions of household income. We used household income to categorise households into tertiles from the poorest (tertile 1) to least poor (tertile 3). We used Kruskal-Wallis tests to compare costs as a proportion of household income across household income tertiles. ${ }^{30}$ We also evaluated catastrophic health expenditure (CHE) as costs exceeding a specified threshold of household available resources. ${ }^{31}$ In this analysis, we used household income as a measure of available resources and set the base threshold as $25 \% .^{1432} 33 \mathrm{We}$ defined costs as catastrophic if they exceeded $25 \%$ of household monthly income $\left(\mathrm{CHE}_{25}\right)$ and also explored impact at $10 \%\left(\mathrm{CHE}_{10}\right)$ and $40 \%\left(\mathrm{CHE}_{40}\right)$ thresholds. We used multivariable logistic regression models to identify factors associated with $\mathrm{CHE}_{25}$. Independent variables that were associated with $\mathrm{CHE}_{25}$ at significance level $\mathrm{p}=0.1$ were sequentially added to the model and kept if they were significantly associated with $\operatorname{cost}(\mathrm{p}<0.05)$ or changed effects of included variables. Excluded variables were then re-introduced to check if they further changed the effect sizes of included variables. Adjusted ORs and $p$ values from the likelihood ratio test (LRT) are reported.

\section{Sensitivity analysis}

We conducted one-way sensitivity analyses of provider costs by varying the source of bed-day costs. We used the average cost per inpatient bed-day for tertiary and secondary facilities in Nigeria from the WHO-CHOICE after accounting for inflation and adjusting to 2020 rates. ${ }^{34}$ We also conducted a sensitivity analysis of indirect costs by using the willingness to pay (WTP) approach to assess productivity loss. Indirect costs using WTP approach were calculated as the product of the amount caregivers were willing to pay for main activity they would have been otherwise engaged in and the total days taken off from work due to childcare.

\section{Patient involvement}

Patients were not directly involved in the design, conduct, reporting or dissemination plans of this research.

\section{RESULTS \\ Study participants}

Overall, 480 out of 495 caregivers of eligible children consented to be interviewed. A total of 480 children (244 outpatient pneumonia, 117 inpatient pneumonia, 53 meningitis and 66 septicaemia) were enrolled (see online supplemental table S2). Of these, $387(81 \%)$ children were aged $\geq 1$ year. Clinical pneumonia cases were younger than their counterparts with meningitis or septicaemia (mean age, 19 vs 25 months, $\mathrm{p}=0.002$ ). Caregivers were aged 20-48 years, mostly mothers, had at least secondary school level education and were employed. Caregivers of children with outpatient pneumonia were more likely to be unemployed compared with those with hospitalised children $(20 \%$ vs $3 \%, \mathrm{p}=<0.0001)$. The mean duration of hospitalisation was 5 days for cases with pneumonia or septicaemia but 7 days for those with meningitis. Majority $(362 / 480,75.4 \%)$ of the children had sought care prior to index visit/hospitalisation.

\section{Provider costs for outpatient pneumonia}

The median provider cost for outpatient pneumonia was US\$17 (IQR: 14-22), and was higher in AKTH (US\$20, IQR: 14-23) compared with MMSH (US\$16; IQR: 14-19, $\mathrm{p}=0.0002)$. Overall, costs for outpatient clinic visit, medications and investigations accounted for $43 \%, 37 \%$ and $20 \%$ of provider costs. The median costs for laboratory investigations were higher in AKTH US\$7 (IQR: 0-8) compared with MMSH US\$0 (IQR: 0-4, p<0.0001). Medications costs were similar between the two hospitals. Median expenses on seeking care elsewhere prior to index presentation were US\$9 (IQR: 0-13) in AKTH and US\$8 (IQR: $5-13)$ in MMSH ( $\mathrm{p}=0.70)$.

\section{Provider costs for hospitalised children}

The respective median/mean provider costs, as shown in table 2, were highest for meningitis in both hospitals which was mostly driven by bed-day costs. The median provider costs (all syndromes combined) were significantly higher in AKTH (US\$359, IQR: 308-400) compared with MMSH (US\$223, IQR: 196-264, p<0.0001).

\section{Household costs for hospitalised children}

Median household income was similar between disease categories but was significantly higher (all syndromes 
Table 2 Provider costs for inpatient pneumonia, meningitis and septicaemia in US\$

\section{Cost US\$}

\begin{tabular}{|c|c|c|c|c|c|c|c|}
\hline & \multicolumn{2}{|c|}{ Inpatient pneumonia } & \multicolumn{2}{|l|}{ Septicaemia } & \multicolumn{2}{|l|}{ Meningitis } & \multirow[b]{2}{*}{$P$ value } \\
\hline & Mean (SD) & Median (IQR) & Mean (SD) & Median (IQR) & Mean (SD) & Median (IQR) & \\
\hline \multicolumn{8}{|l|}{ AKTH } \\
\hline $\begin{array}{l}\text { Length of stay } \\
\text { (days) }\end{array}$ & $5(0.8)$ & $5.0(4-5)$ & $5(1.3)$ & $5(5-6)$ & $6(1.1)$ & $6(6-7)$ & $<0.001$ \\
\hline \multicolumn{8}{|l|}{ Provider costs } \\
\hline Bed-day costs & $272(45)$ & 277 (222-278) & $297(70)$ & 277 (277-333) & $351(59)$ & $332(332-388)$ & $<0.001$ \\
\hline Drugs & $16(6)$ & $15(13-17)$ & $19(6)$ & $18(16-20)$ & $20(3)$ & $20(18-22)$ & $<0.001$ \\
\hline Investigations & $15(6)$ & $14(13-14)$ & $14(7)$ & $14(7-21)$ & $17(7)$ & $20(13-22)$ & 0.23 \\
\hline Special services* & $46(21)$ & $40(30-60)$ & $25(36)$ & $0(0-54)$ & $32(31)$ & $34(0-40)$ & $<0.001$ \\
\hline Total provider costs & $348.6(63.0)$ & $347(301-372)$ & $354.0(103.4)$ & $325(300-380)$ & $420.0(80.1)$ & 407 (364-449) & 0.001 \\
\hline \multicolumn{8}{|l|}{ MMSH } \\
\hline $\begin{array}{l}\text { Mean admission } \\
\text { days (SD) }\end{array}$ & $6(3.3)$ & $5(5-6)$ & $6(1.5)$ & $5(5-7)$ & $7(4.8)$ & $6(5-7)$ & 0.004 \\
\hline \multicolumn{8}{|l|}{ Provider costs } \\
\hline Bed-day costs & $189.1(110.3)$ & $166(166-200)$ & $186.0(50.6)$ & 166 (166-233) & $237.2(161.3)$ & 199 (166-233) & 0.004 \\
\hline Drugs & $17.7(11.7)$ & $16(11-20)$ & $17.8(6.4)$ & $17(14-22)$ & $21.5(7.9)$ & $19(17-24)$ & 0.01 \\
\hline Investigations & $7.1(2.6)$ & $8(7-8)$ & $7.0(2.5)$ & $7(4-8)$ & $8.6(1.4)$ & $8(7-10)$ & $<0.001$ \\
\hline Special services* & $27.9(13.3)$ & $30(20-30)$ & $16.5(20.3)$ & $14(0-30)$ & $29.6(19.4)$ & $30(20-40)$ & 0.001 \\
\hline Total provider costs & 241.8 (116.9) & $219(220-247)$ & $227.3(67.6)$ & 206 (179-264) & 296.9 (117.5) & 257 (225-280) & 0.002 \\
\hline Combined hospitals & $285.6(111.4)$ & $265(215-347)$ & $288.7(107.2)$ & $298(196-335)$ & $345.7(158.0)$ & $294(253-408)$ & 0.01 \\
\hline
\end{tabular}

${ }^{*}$ Oxygen and blood transfusion.

AKTH, Aminu Kano Teaching Hospital; MMSH, Murtala Muhammed Specialist Hospital.

combined) for those presenting to AKTH (US\$250, IQR: 222-277, $\mathrm{p}=0.02$ ) compared with MMSH (US\$222, IQR: 194-277). Majority of caregivers (217/236, 92\%) reported using a combination of current income and savings to cover expenses. Only about 3\% reported using other sources such as borrowing, asking relatives or selling assets to cover expenses.

Median direct household costs as shown in table 3 were highest for meningitis and lowest for pneumonia in both hospitals. However, there was no significant difference in overall direct household costs between the two hospitals. Direct costs comprised mostly of user fees, and for each disease category in both hospitals, medication costs were the largest fraction of user fees (online supplemental figure S1A, B).

Median indirect costs were lowest for inpatient pneumonia compared with meningitis or septicaemia, as shown in table 3. Comparison between the hospitals (all syndromes combined), showed indirect costs were slightly higher in AKTH compared with MMSH (US\$22 (IQR: 15-26) vs US\$18 (IQR: 10-23), p=0.04).

\section{Economic impact to households}

The poorest households spent a median of $25 \%$ of their monthly income directly on treatment costs and lost an additional $8 \%$ from loss of caregiver time, compared with $13 \%$ of income and $6 \%$ of caregiver time for the least poor households (data not shown). Treatment costs as fractions of monthly household income were inversely related to household income tertiles (see online supplemental table S3).

Table 4 shows the proportion of households encountering $\mathrm{CHE}_{25}$ at different threshold cut-off values across household income levels. CHE was substantial, and at $10 \%$ threshold nearly all households across all income levels encountered CHE. CHE increased with decreasing household income level. This inverse relationship is further illustrated in figure 1 which shows that as the threshold values increase, the proportions of households encountering catastrophic costs declines steeply for the higher income households, with slowest decline for the poorest households (tertile 1).

Admitting hospital (MMSH), meningitis or septicaemia, seeking care at a private hospital prior to admission and higher provider costs were associated with increased odds of $\mathrm{CHE}_{95}$, while having $\geq 3 \mathrm{U} 5$ children and higher indirect costs lowered the odds of $\mathrm{CHE}_{25}$ (see table 5).

\section{Sensitivity analyses}

Provider costs were sensitive to source of hospital (bedday) costs. Provider costs were between $38 \%$ and $40 \%$ lower across all disease categories and between the hospitals when the WHO-CHOICE estimates were used (online supplemental table S4) compared with actual hospital admission costs (online supplemental table S4). 


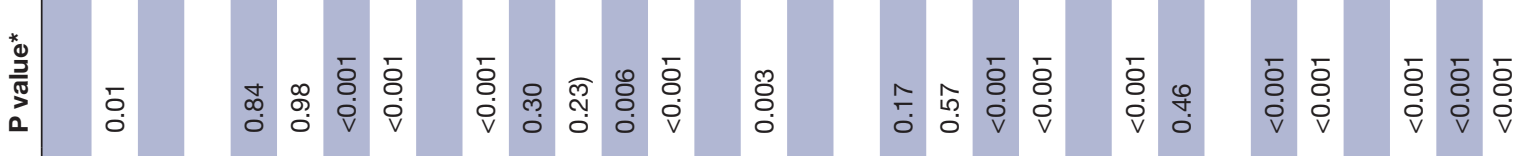

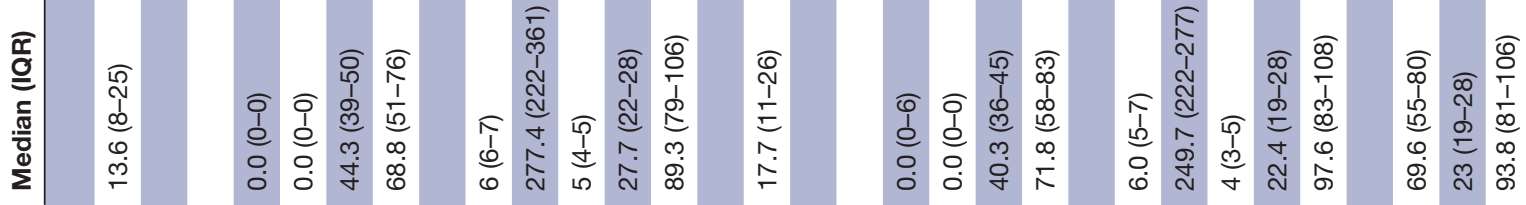

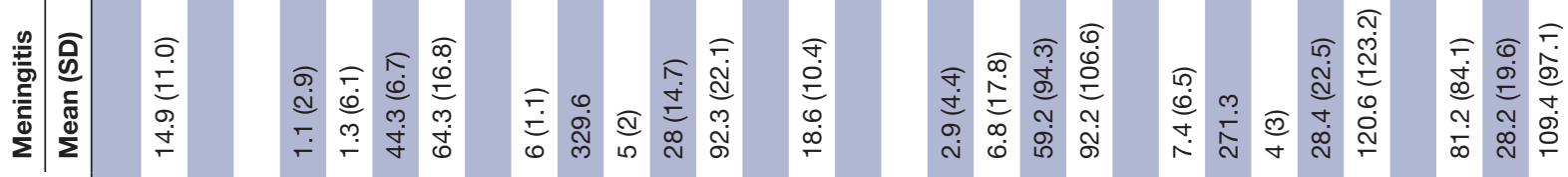

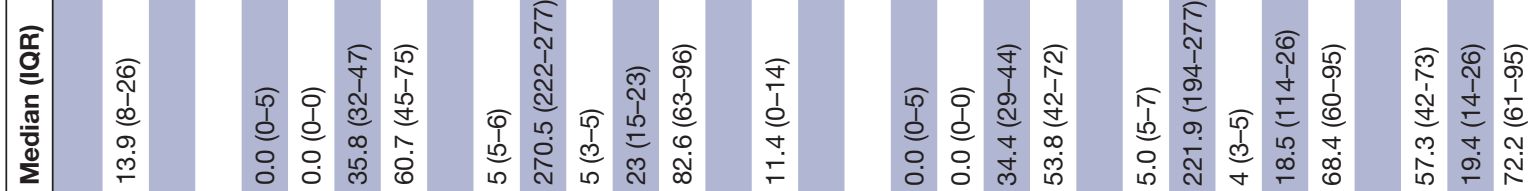

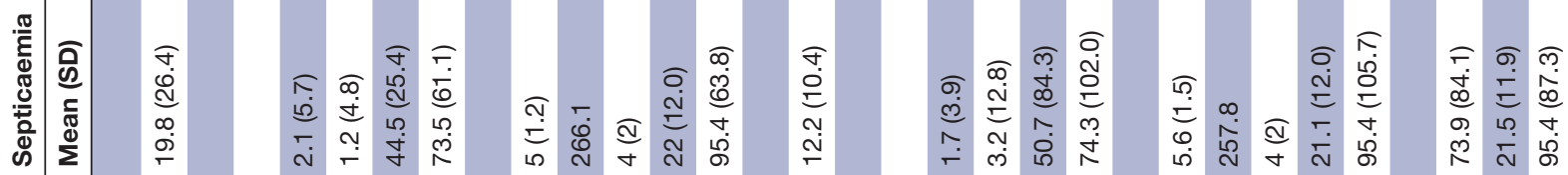

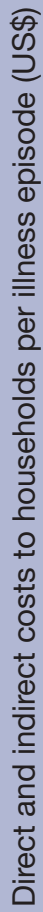

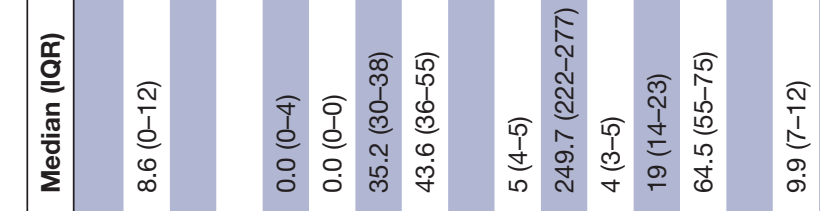

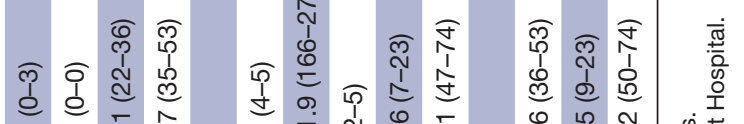

ลิ

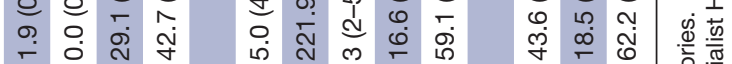

产 $\frac{\pi}{0}$

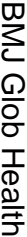

$\overrightarrow{\mathrm{F}}$

음

$\frac{\bar{\sigma}}{\overline{0}}$

œ

$\vec{\omega}$

잉.

只

¿े

일

$\underline{\omega}$

离

N

문

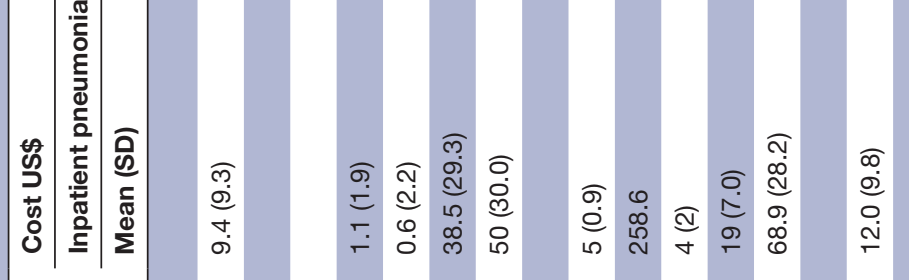

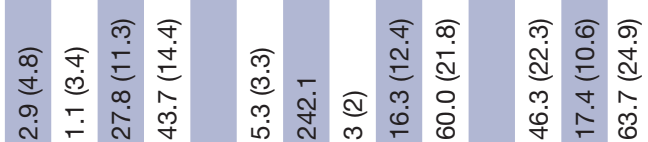

o 更

号

is

这 $\frac{\pi}{\pi}$

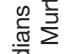

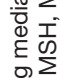

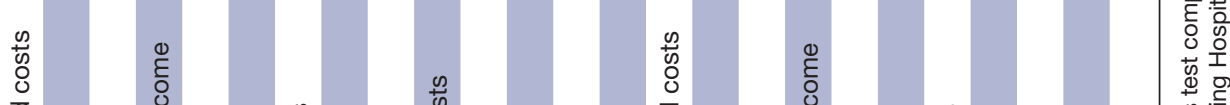

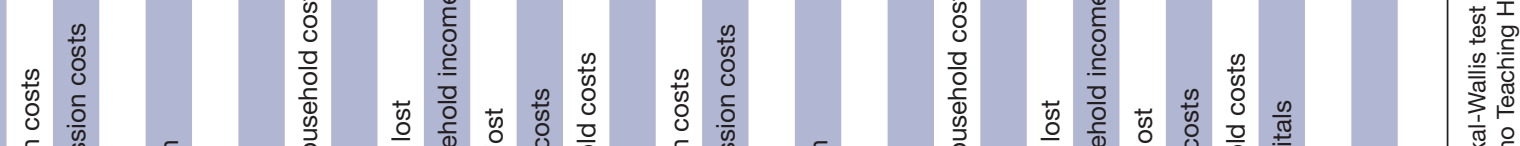

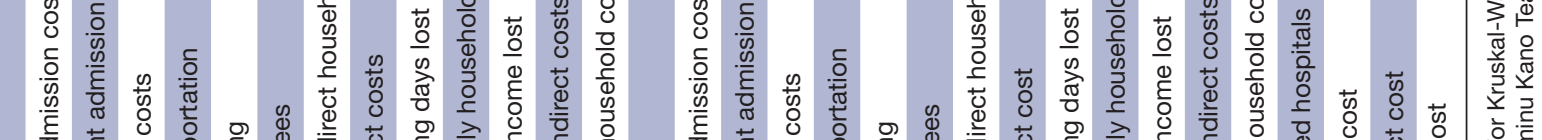

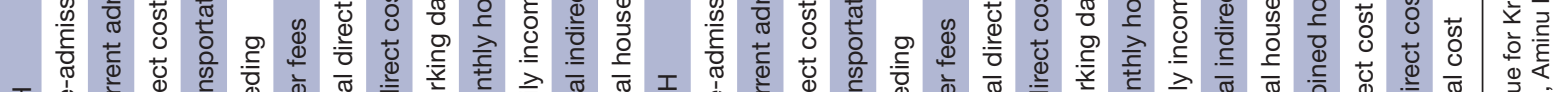


Table 4 Proportions of households with CHE at different thresholds of household income

\begin{tabular}{|c|c|c|c|c|c|c|}
\hline \multirow[b]{3}{*}{ Income tertile } & \multicolumn{6}{|c|}{ CHE threshold level } \\
\hline & \multicolumn{2}{|l|}{$10 \%$} & \multicolumn{2}{|l|}{$25 \%$} & \multicolumn{2}{|l|}{$40 \%$} \\
\hline & $\%$ & $95 \% \mathrm{Cl}$ & $\%$ & $95 \% \mathrm{Cl}$ & $\%$ & $95 \% \mathrm{Cl}$ \\
\hline Tertile 1 (poorest) & 97.2 & 92.2 to 99.4 & 53.2 & 43.4 to 62.8 & 18.3 & 11.6 to 26.9 \\
\hline Tertile 2 & 97.2 & 90.3 to 99.7 & 25.0 & 15.5 to 36.6 & 2.8 & 0.3 to 9.7 \\
\hline Tertile 3 (least poor) & 81.8 & 69.1 to 90.9 & 3.6 & 0.4 to 12.5 & 0.0 & 0.0 to 0.0 \\
\hline Overall & 93.6 & 89.7 to 96.1 & 33.1 & 27.1 to 39.4 & 9.3 & 5.9 to 13.7 \\
\hline
\end{tabular}

CHE, catastrophic health expenditure.

Indirect costs were also sensitive to approach used as costs were higher for all conditions in both hospitals with the WTP (online supplemental table S4) compared with the HCA. However, in contrast to HCA, indirect costs were similar between the hospitals $(\mathrm{p}=0.45)$

\section{DISCUSSION}

In this study, we estimated the costs of treatment of clinical pneumonia, septicaemia and meningitis in Nigerian children as well as the economic impact of these costs on households. Costs varied by hospital as they were higher in the tertiary hospital (AKTH) for all disease categories. Provider costs also varied by illness and were highest for meningitis irrespective of hospital. Costs to households were similar between the hospitals but highest for meningitis and lowest for pneumonia. The economic impact to households was considerable with total costs to households ranging between $25 \%$ and $37 \%$ of monthly household income for 5-7 days of hospitalisation. One-third of the households incurred CHE at 25\% threshold and the poorest households bore the greatest burden of CHE.

Although provider costs are likely to vary across the country and between hospitals, when applied to the global burden of disease and the proportions of the different pneumococcal disease syndromes, our cost estimates translate to annual provider costs of $>$ US $\$ 110$ million, that is, $\sim 9 \%$ of Nigeria's 2020 health budget. ${ }^{135}$ Funding of

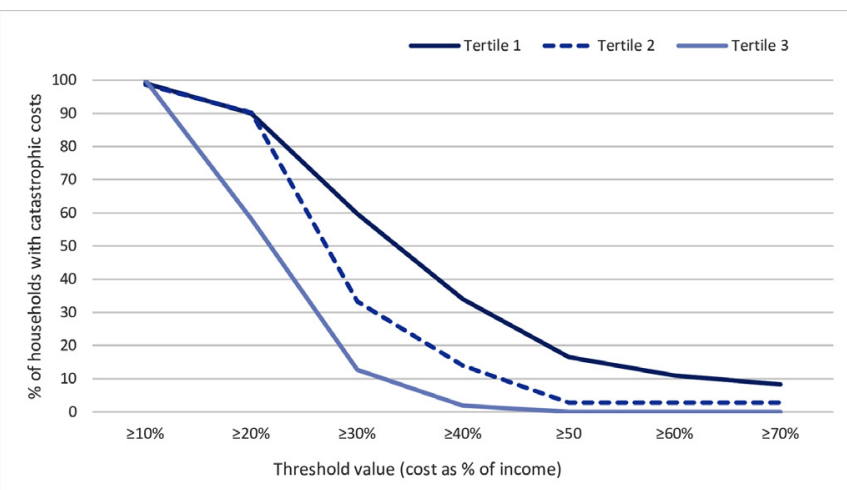

Figure 1 Distribution of proportions of households encountering catastrophic costs at different threshold values of cost as a fraction of household income by tertiles of household income level. Tertiles range from the poorest households (tertile 1) to the least poor (tertile 3). provider costs within the public sector is largely through budgetary allocations at the federal and state levels, and the overall health sector budget has been consistently below the $15 \%$ threshold of the total annual budget agreed to in the Abuja declaration. ${ }^{35} 36$ Treatment of pneumococcal disease exerts undue strain on the health sector, particularly at the tertiary hospitals where unit costs are higher for most components as reported elsewhere. ${ }^{578}$ In many settings, robust pneumococcal disease surveillance has shown evidence of substantial reduction in pneumococcal diseases attributed to PCV use. ${ }^{37}$ The extent of savings on treatment costs will depend on the effectiveness and coverage of PCV across the country.

For each IPD category and hospital in our study, 'hospital stay' accounted for the largest proportion of provider costs. This is similar to findings in diverse settings across Africa (Kenya and The Gambia), Asia (India and Vietnam) and South America. ${ }^{6-10} 38$ This indicate the huge recurrent costs of hospitalisation and inpatient care to the healthcare system. Specialised services were the next largest contributor to provider costs, and they were mainly driven by oxygen costs particularly for pneumonia where oxygen administration was nearly universal indicating the severity of disease. In The Gambia, these services contributed marginally to the total provider costs. This is because oxygen costs per day in our study was $>10$-fold the estimates in The Gambia. ${ }^{9}$ Outside sSA, provider cost estimates tend to be considerably higher than our findings regardless of data source for bed-day costs and whether capital costs were also included. ${ }^{6} 103940$ A multicountry study in Brazil, Chile and Uruguay estimating only recurrent costs reported hospitalisation costs $>10$-fold with corresponding high provider costs ranging from US $\$ 75$ for pneumonia to US $\$ 5436$ for meningitis. In Pakistan, when capital costs were included, provider costs ranged between US\$71 for pneumonia and US\$2043 for meningitis. ${ }^{39}$

We found substantial household costs ranging from US $\$ 44$ for pneumonia to US\$72 for meningitis. These figures are higher than reported for malaria in Nigeria, which ranged from $\sim \mathrm{US} \$ 7$ for outpatients to $\sim \mathrm{US} \$ 10$ for hospitalised $\operatorname{cases}^{41}{ }^{42}$; but was lower than seen for chronic conditions, such as sickle cell anaemia (US\$240) and Buruli ulcer (US\$135). ${ }^{43}$ These variations are attributable to differences in resource use, type of 
Table 5 Distribution of $\mathrm{CHE}_{25}$ and multivariable logistic regression of factors associated with $\mathrm{CHE}_{2}$

\begin{tabular}{|c|c|c|c|c|}
\hline & $\begin{array}{l}\text { Total } \\
\mathrm{N}=236\end{array}$ & $\begin{array}{l}\mathrm{CHE}_{25} \\
\mathrm{~N}=78\end{array}$ & Adjusted ${ }^{*}$ OR $(95 \% \mathrm{Cl})$ & $P$ value \\
\hline \multicolumn{5}{|l|}{ Hospital, n (\%) } \\
\hline AKTH & 101 & $29(28.7)$ & Reference & \\
\hline MMSH & 135 & 49 (36.3) & 3.6 (1.4 to 9.5$)$ & 0.005 \\
\hline \multicolumn{5}{|l|}{ IPD category, n (\%) } \\
\hline Pneumonia & 117 & $26(22.2)$ & Reference & \\
\hline Septicaemia & 66 & $26(39.4)$ & 2.5 (1.1 to 5.5$)$ & \\
\hline Meningitis & 53 & $26(49.1)$ & $3.2(1.3$ to 8.3$)$ & 0.02 \\
\hline \multicolumn{5}{|l|}{ Pre-admission care seeking } \\
\hline None & 72 & $19(26.4)$ & Reference & \\
\hline Private & 58 & $31(53.5)$ & $4.3(1.8$ to 10.5$)$ & \\
\hline Chemist & 106 & $28(26.4)$ & $0.8(0.4$ to 1.9$)$ & $<0.001$ \\
\hline \multicolumn{5}{|l|}{ Age of caregiver in years, $\mathrm{n}(\%)$} \\
\hline$<30$ & 143 & $44(30.8)$ & Reference & \\
\hline$\geq 30$ & 93 & $34(36.6)$ & $1.1(0.5$ to 2.4$)$ & 0.75 \\
\hline \multicolumn{5}{|c|}{ Caregivers with salaried occupation, n (\%) } \\
\hline No & 112 & $49(43.8)$ & Reference & \\
\hline Yes & 124 & $29(23.4)$ & $0.5(0.2$ to 0.9$)$ & 0.04 \\
\hline \multicolumn{5}{|l|}{ Age of child in months, $\mathrm{n}(\%)$} \\
\hline $1-11$ & 36 & $7(19.4)$ & $0.4(0.2$ to 1.3$)$ & \\
\hline $12-23$ & 103 & $32(31.1)$ & Reference & \\
\hline$\geq 24$ & 97 & $39(40.2)$ & $1.2(0.6$ to 2.5$)$ & 0.16 \\
\hline \multicolumn{5}{|l|}{ No of children <5years, n (\%) } \\
\hline$<3$ & 135 & 53 (39.3) & Reference & \\
\hline$\geq 3$ & 101 & $25(24.8)$ & $0.3(0.2$ to 0.7$)$ & 0.003 \\
\hline Provider cost (US\$10), mean (SD) & $300.0(108.6)$ & $330.0(147.3)$ & 1.09 (1.03 to 1.15$)$ & $<0.001$ \\
\hline Indirect cost† (US\$10), mean (SD) & $21.0(14.1)$ & $19.9(15.5)$ & $0.6(0.4$ to 0.8$)$ & 0.001 \\
\hline
\end{tabular}

${ }^{*}$ Adjusted for all variables in the table.

†Using human-capital approach.

AKTH, Aminu Kano Teaching Hospital; CHE, catastrophic health expenditure; IPD, invasive pneumococcal disease; MMSH, Murtala Muhammed Specialist Hospital.

and duration of illness. User fees in our study contributed to more than two-thirds of direct household costs and were largely driven by medications costs. In The Gambia, where treatment was provided at no cost to families, household OOP costs were mainly driven by non-healthcare costs including meals and visitors. ${ }^{9}$ The main caregivers reported losing between 5 and 7 working days over the illness period. Although working days lost by caregivers were similar between household income levels, income loss had greater impact in the poorest households where more than half of the caregivers were also self-employed. In contrast, $80 \%$ of caregivers in the least poor households had regular salaried jobs and were likely to also receive full pay during absence for a short illness duration.

Costs incurred during treatment had considerable economic impact to households particularly for large households dependent on little income. With large numbers of economic dependents per household, that is, non-income earning household members, a 1-week illness of one child, resulted in $\mathrm{CHE}_{25}$ in one-third of households. We note the differences in CHE in ours compared with other studies in Nigeria. Although several studies analysed nationally-representative surveys, their findings differ from ours because they do not address a specific illness, target chronic conditions and may have limited applicability to our study setting due to subnational differences in healthcare seeking behaviour. ${ }^{18} 4546$ At $\mathrm{CHE}_{10}$, the cost of treatment costs had significant burden on households regardless of their income. At higher thresholds, our results are similar to others including those that used household income as a measure of available resources like we did. ${ }^{184344} 4647$

Unplanned treatment expenses are likely to affect other household expenditures. OOP payment for healthcare can provide obstacles for treatment access particularly 
to the poorest, skewing treatment seeking towards only those that can afford to pay. ${ }^{48}$ The higher proportion of unemployed caregivers presenting outpatient compared with inpatient may be an indicator of reduced access to hospitalised care by poorer households. The differences in household income levels between the hospitals show a preference for the secondary hospital by poorer households. We assume that this preference is largely due to the state policy of subsidised health services for children aged $<5$ years in the secondary hospital. ${ }^{20}$ Yet these households still incurred greater burden of costs as a fraction of their income, suggesting that 'free care' to U5s provided by the state government does not translate into lower costs to households compared with the tertiary hospital. This may be the case because drugs and medical consumables are usually excluded from these subsidised care and when they are included, they are usually out-of-stock, meaning families have to get them from other providers and often at higher OOP costs. ${ }^{48} \mathrm{CBHI}$ is currently being implemented in many states across Nigeria including Kano state and primarily targets the formal sector with expanding cover to vulnerable groups (women and children), informal sector and rural areas. However, we show that admissions at the state facility (MMSH) where services are supposed to 'free' and U5s covered by the $\mathrm{CBHI}$, increased the odds of $\mathrm{CHE}_{25}$ almost fourfold. This suggests that the benefits of the contributory scheme are yet to reach this target population, possibly due to lack of awareness and unwillingness to pre-pay for CBHI. ${ }^{21}$

Having a salaried job, $\geq 3$ children U5 in the household and higher indirect costs (HCA) reduced the odds of $\mathrm{CHE}_{25}$. OOP payment from available household resources is the predominant way of financing healthcare in Nigeria. However, other non-health expenditures (rent, utilities and education) are financed with the same household resources as healthcare, and if substantial, can reduce resources 'available' for health expenditure. ${ }^{45} \mathrm{We}$ did not collect information to assess the magnitude of non-health expenses incurred by households. But having other young children or productivity losses are circumstances that can reduce resources available to households explaining their association with reduced odds of CHE. Conversely, provider costs and seeking care at a private hospital prior to hospitalisation increased odds of CHE, illustrating how burden of provider costs are pushed to households.

This study has some limitations. First, the costs here do not account for full costs to the provider because capital costs are excluded due to challenges in accessing such data. Second, we collected data on household costs on admission and close to or at discharge to limit bias because admission duration was short. However, there is still a risk of recall bias. Second, costs exclude children who died during admission and may have incurred costs from higher resource use due to more severe disease. Third, we only estimated time loss for the primary caregiver in hospital which does extend to fathers or other household members. Another limitation is the use of monthly income rather than household (or non-food) expenditure to assess CHE which may not identify the different ways of health financing. However, we believe current income reflects current resources and captures the current household capacity to pay for expenses of treatment given the short-term duration of illness. That majority of caregivers reported using both current income and savings to cover healthcare expenses supports our decision to use current income rather than long-term household asset. Lastly, subnational differences in household incomes may limit generalisability of our findings, particularly the costs to household cost and its economic impact. However, some components of provider costs such as bed-day costs are not likely to differ at the tertiary hospital level because these hospitals are directly funded by the Federal Government. Additionally, because many states also offer subsidised health services to children at the secondary, our findings may be generalisable to such settings.

\section{CONCLUSIONS}

Our analyses illustrate the treatment costs of pneumococcal disease to providers and households in Nigeria. Hospitalisation particularly at tertiary level is associated with substantial costs to both the provider and households. Households incur expenses prior to diagnosis and incur substantial direct and indirect costs that has significant impact on their incomes.

Our findings have important implications for policy. First, it is evident that the PCV programme, by averting disease, can free up scarce resources for the health sector to divert to competing health problems, reduce unexpected expenditures and CHEs and increase resources within household for savings and essential non-health expenditures. So, it is essential to achieve and maintain high PCV coverage levels to reduce this financial burden, especially for the poorer households. Second, due to higher cost of providing care at the tertiary level, strengthening lower levels of care to provide early treatment will also significantly reduce provider costs and reduce strain on the health sector resources. Finally, the current mechanisms for financing health expenditures are inadequate to protect households from catastrophic expenses. Given that OOP payments were mainly driven by medication costs, the state government when declaring 'free' health services should have a realistic plan for uninterrupted supply of drugs and other essential commodities/ consumables to ensure that the families are not obliged to pay for these OOP.

\footnotetext{
Author affiliations

${ }^{1}$ Epidemiology and Demography, KEMRI-Wellcome Trust Research Programme, Kilifi, Kenya

${ }^{2}$ Infectious Diseases Epidemiology, London School of Hygiene and Tropical Medicine, London, UK

${ }^{3}$ Community Medicine, Aminu Kano Teaching Hospital, Kano, Nigeria ${ }^{4}$ Community Medicine, Bayero University Faculty of Medicine, Kano, Nigeria

${ }^{5}$ Paediatrics, Bayero University Faculty of Medicine, Kano, Nigeria

${ }^{6}$ Paediatrics, Aminu Kano Teaching Hospital, Kano, Nigeria
} 
${ }^{7}$ Paediatrics, Murtala Muhammed Specialist Hospital, Kano, Nigeria

${ }^{8}$ Health System \& Research Ethics, KEMRI-Wellcome Trust Research Programme, Kilifi, Kenya

Twitter Ifedayo M Adetifa @IfedayoTiffy

Acknowledgements The authors are grateful to the staff of the paediatric units of Aminu Kano Teaching Hospital and Murtala Muhammed Specialist Hospital for facilitating the data collection.

Contributors ALA, AS and IMA conceptualised the study. ALA, IMA, J0 and JJ designed the study. ALA led the data collection with supervision from IMA. BK led the design of database and data entry. ALA analysed the data with input from IMA and JJ. ALA interpreted the data with guidance from IMA, JJ, AS, and SG. ALA wrote the first draft. ALA, BK, MMB, MGJ, SG, JO, AS, JJ and IMA reviewed successive drafts and approved the final version of the manuscript. ALA and IMA acted as guarantor of this study.

Funding This work was supported through the DELTAS Africa Initiative (DEL15-003). The DELTAS Africa Initiative is an independent funding scheme of the African Academy of Sciences (AAS)'s Alliance for Accelerating Excellence in Science in Africa (AESA) and supported by the New Partnership for Africa's Development Planning and Coordinating Agency (NEPAD Agency) with funding from the Wellcome Trust (107769/Z/10/Z) and the UK government. The views expressed in this publication are those of the author(s) and not necessarily those of AAS, NEPAD Agency, Wellcome Trust or the UK government. IMA is funded by the UK's Medical Research Council and Department For International Development through an African Research Leader Fellowship (MR/S005293/1) and by the NIHR-MPRU at UCL (grant 2268427 LSHTM). AS is funded by a Wellcome Trust Senior Research Fellowship (214320) and the NIHR Health Protection Research Unit in Immunisation. J0 is funded by the NIHR Global Health Research Unit on Mucosal Pathogens (16/136/46). The funders had no role in the study design, data collection, data analysis, data interpretation or writing of the report.

Competing interests None declared.

\section{Patient consent for publication Not applicable.}

Ethics approval This study involves human participants and was approved by Aminu Kano Teaching Hospital Research Ethics Committee - NHREC/21/08/2008/ AKTH/EC/2165 and Kano State Ministry of Health Research Ethics Committee - MOH/ OFF/797/T.//596, Kenya Medical Research Institute Scientific and Ethical Review Unit SERU 3350, London School of Hygiene and Tropical Medicine Observational/ Interventions Research Ethics Committee - Ref 11670. Participants gave informed consent to participate in the study before taking part.

Provenance and peer review Not commissioned; externally peer reviewed.

Data availability statement Data are available upon reasonable request. Data supporting findings are included in the manuscript and supplement. Additional data requests can be made to the KEMRI-Wellcome Trust Research Programme Data Governance Committee (dgc@kemri-wellcome.org).

Supplemental material This content has been supplied by the author(s). It has not been vetted by BMJ Publishing Group Limited (BMJ) and may not have been peer-reviewed. Any opinions or recommendations discussed are solely those of the author(s) and are not endorsed by BMJ. BMJ disclaims all liability and responsibility arising from any reliance placed on the content. Where the content includes any translated material, BMJ does not warrant the accuracy and reliability of the translations (including but not limited to local regulations, clinical guidelines, terminology, drug names and drug dosages), and is not responsible for any error and/or omissions arising from translation and adaptation or otherwise.

Open access This is an open access article distributed in accordance with the Creative Commons Attribution 4.0 Unported (CC BY 4.0) license, which permits others to copy, redistribute, remix, transform and build upon this work for any purpose, provided the original work is properly cited, a link to the licence is given, and indication of whether changes were made. See: https://creativecommons.org/ licenses/by/4.0/.

\section{ORCID iDs}

Aishatu Lawal Adamu http://orcid.org/0000-0002-6330-1033

Ifedayo M Adetifa http://orcid.org/0000-0003-2556-9407

\section{REFERENCES}

1 Wahl B, O'Brien KL, Greenbaum A, et al. Burden of Streptococcus pneumoniae and Haemophilus influenzae type $B$ disease in children in the era of conjugate vaccines: global, regional, and national estimates for 2000-15. Lancet Glob Health 2018;6:e744-57.

2 GBD 2015 Mortality and Causes of Death Collaborators. Global, regional, and national life expectancy, all-cause mortality, and causespecific mortality for 249 causes of death, 1980-2015: a systematic analysis for the global burden of disease study 2015. Lancet 2016;388:1459-544.

3 O'Brien KL, Wolfson LJ, Watt JP, et al. Burden of disease caused by Streptococcus pneumoniae in children younger than 5 years: global estimates. Lancet 2009;374:893-902.

4 Chen C, Cervero Liceras F, Flasche S, et al. Effect and costeffectiveness of pneumococcal conjugate vaccination: a global modelling analysis. Lancet Glob Health 2019;7:e58-67.

5 Zhang S, Sammon PM, King I, et al. Cost of management of severe pneumonia in young children: systematic analysis. $J$ Glob Health 2016;6:010408.

6 Constenla D. Evaluating the costs of pneumococcal disease in selected Latin American countries. Rev Panam Salud Publica 2007:22:268-78.

7 Madsen HO, Hanehøj M, Das AR, et al. Costing of severe pneumonia in hospitalized infants and children aged 2-36 months, at a secondary and tertiary level hospital of a not-for-profit organization. Trop Med Int Health 2009;14:1315-22.

8 Ayieko P, Akumu AO, Griffiths UK, et al. The economic burden of inpatient paediatric care in Kenya: household and provider costs for treatment of pneumonia, malaria and meningitis. Cost Eff Resour Alloc 2009;7:3.

9 Usuf E, Mackenzie G, Sambou S, et al. The economic burden of childhood pneumococcal diseases in the Gambia. Cost Eff Resour Alloc 2016:14:4.

10 Le P, Griffiths UK, Anh DD, et al. The economic burden of pneumonia and meningitis among children less than five years old in Hanoi, Vietnam. Trop Med Int Health 2014;19:1321-7.

11 Griffiths UK, Dieye Y, Fleming J, et al. Costs of meningitis sequelae in children in Dakar, Senegal. Pediatr Infect Dis J 2012;31:e189-95.

12 Akweongo P, Dalaba MA, Hayden MH, et al. The economic burden of meningitis to households in Kassena-Nankana district of northern Ghana. PLoS One 2013;8:e79880.

13 World Bank Group. Nigeria living standards survey:a survey report by the nigerian national bureau of statistics (2018/2019. National Bureau of Statistics, 2020.

14 WHO. Financial protection. Available: https://www.who.int/data/gho/ data/themes/topics/financial-protection [Accessed 12 May 2021]

15 Uzochukwu BSC, Ughasoro MD, Etiaba E, et al. Health care financing in Nigeria: implications for achieving universal health coverage. Niger J Clin Pract 2015;18:437-44.

16 Alawode GO, Adewole DA. Assessment of the design and implementation challenges of the National health insurance scheme in Nigeria: a qualitative study among sub-national level actors, healthcare and insurance providers. BMC Public Health 2021:21:124.

17 Barasa E, Kazungu J, Nguhiu P, et al. Examining the level and inequality in health insurance coverage in 36 sub-Saharan African countries. BMJ Glob Health 2021;6:e004712.

18 Aregbeshola BS, Khan SM, Payments O-of-P. Out-Of-Pocket payments, catastrophic health expenditure and poverty among households in Nigeria 2010. Int $J$ Health Policy Manag 2018;7:798-806.

19 Chuma J, Gilson L, Molyneux C. Treatment-seeking behaviour, cost burdens and coping strategies among rural and urban households in coastal Kenya: an equity analysis. Trop Med Int Health 2007;12:673-86.

20 Surajo AZ, Musa J, Umar AS. An integrated approach to social protection system in Kano state, Nigeria: a sustainable development linkage. International Journal of Modern Trends in Social Sciences 2019;2:48-62.

21 Abubakar SS, Saleh J-EA. Awareness and willingness to pay for community-based health insurance scheme among patients: a case study of the orthopaedic unit of Murtala Mohammed specialist Hospital Kano, northwest Nigeria. OAlib 2021;08:1-8.

22 Bijleveld P, Lasri N. Successfully transitioning Nigeria from Gavi support, 2018.

23 National population estimates. GRID3 Nigeria. Available: https:// grid3.gov.ng/datasets?\&sector=\%5B\%22population $\% 22 \% 5 \mathrm{D}$ [Accessed 14 Apr 2021].

24 Weber EM, Seaman VY, Stewart RN, et al. Census-independent population mapping in northern Nigeria. Remote Sens Environ 2018;204:786-98.

25 National Bureau of statistics (Nbs). Multiple indicator cluster survey 2016-17, survey findings report, 2018. Available: https://www.unicef. 
org/nigeria/reports/multiple-indicator-cluster-survey-2016-17-mics [Accessed 07 May 2019].

26 Charan J, Biswas T. How to calculate sample size for different study designs in medical research? Indian J Psychol Med 2013;35:121-6.

27 Dhand NK, Khatkar MS. Statulator: an online statistical calculator. sample size calculator for estimating a mean, 2014. Available: http:// statulator.com/SampleSize/ss1M.html\# [Accessed 02 Oct 2019].

28 Divkolaye N, Seighali F, Pourfathollah AA, et al. A country-wide comparison of cost recovery and financing systems of blood and blood products. East Mediterr Health J 2019;25:104-10.

29 Central bank of Nigeria: monthly average exchange rates of the Naira. Available: https://www.cbn.gov.ng/rates/exrate.asp [Accessed 03 Jan 2021].

30 Foster N, Vassall A, Cleary S, et al. The economic burden of TB diagnosis and treatment in South Africa. Soc Sci Med 2015;130:42-50.

31 Essue BM, Laba T-L, Knaul F. Economic Burden of Chronic III Health and Injuries for Households in Low- and Middle-Income Countries. In: Disease control priorities: improving health and reducing poverty. Washington (DC: The International Bank for Reconstruction and Development, 2017.

32 Bhojani U, Thriveni B, Devadasan R, et al. Out-of-pocket healthcare payments on chronic conditions impoverish urban poor in Bangalore, India. BMC Public Health 2012;12:990.

33 Klavus J, Kawabata K, Evans D. Household health system contributions and capacity to pay: definitional, empirical, and technical challenges. In: Health systems performance assessment: debate, new methods and new empiricism. Geneva: World Health Organization, 2003.

34 WHO. WHO-CHOICE estimates of cost for inpatient and outpatient health service delivery, 2021. Available: https://www.who.int/ publications $/ \mathrm{m} / \mathrm{item} /$ who-choice-estimates-of-cost-for-inpatientand-outpatient-health-service-delivery [Accessed 19 Nov 2021].

35 Adebisi YA, Umah JO, Olaoye OC, et al. Assessment of health budgetary allocation and expenditure toward achieving universal health coverage in Nigeria. Int J Health Life Sci 2020;6.

36 Enabulele O. Achieving universal health coverage in Nigeria: moving beyond annual celebrations to concrete address of the challenges. World Medical \& Health Policy 2020;12:47-59.

37 Lecrenier N, Marijam A, Olbrecht J, et al. Ten years of experience with the pneumococcal non-typeable Haemophilus influenzae protein D-conjugate vaccine (Synflorix) in children. Expert Rev Vaccines 2020:19:247-65.

38 Anh DD, Riewpaiboon A, Tho LH, et al. Treatment costs of pneumonia, meningitis, sepsis, and other diseases among hospitalized children in Viet Nam. $J$ Health Popul Nutr 2010;28:436-42.

39 Hussain $\mathrm{H}$, Waters $\mathrm{H}$, Omer SB, et al. The cost of treatment for child pneumonias and meningitis in the Northern areas of Pakistan. Int $J$ Health Plann Manage 2006;21:229-38.

40 Petit G, De Wals P, Law B, et al. Epidemiological and economic burden of pneumococcal diseases in Canadian children. Can J Infect Dis 2003;14:215-20.

41 Etiaba E, Onwujekwe O, Uzochukwu B, et al. Investigating payment coping mechanisms used for the treatment of uncomplicated malaria to different socio-economic groups in Nigeria. Afr Health Sci 2015;15:42-8.

42 Onwujekwe O, Uguru N, Etiaba E, et al. The economic burden of malaria on households and the health system in Enugu state Southeast Nigeria. PLoS One 2013;8:e78362.

43 Olatunya OS, Ogundare EO, Fadare JO, et al. The financial burden of sickle cell disease on households in Ekiti, Southwest Nigeria. Clinicoecon Outcomes Res 2015;7:545-53.

44 Chukwu JN, Meka AO, Nwafor CC, et al. Financial burden of health care for Buruli ulcer patients in Nigeria: the patients' perspective. Int Health 2017;9:36-43.

45 Ssewanyana S, Kasirye I. Estimating catastrophic health expenditures from household surveys: evidence from living standard measurement surveys (LSMS)-Integrated Surveys on Agriculture (ISA) from Sub-Saharan Africa. Appl Health Econ Health Policy 2020;18:781-8

46 Okedo-Alex IN, Akamike IC, Ezeanosike OB, et al. A review of the incidence and determinants of catastrophic health expenditure in Nigeria: implications for universal health coverage. Int $J$ Health Plann Manage 2019;34:e1387-404.

47 Cleopatra I, Eunice K. Household catastrophic health expenditure: evidence from Nigeria. In: Microeconomics and macroeconomics, 2021.

48 Ameh S, Akeem BO, Ochimana C, et al. A qualitative inquiry of access to and quality of primary healthcare in seven communities in East and West Africa (SevenCEWA): perspectives of stakeholders, healthcare providers and users. BMC Fam Pract 2021;22:45. 